Journal of Advanced Research in Fluid Mechanics and Thermal Sciences

\title{
Numerical Study of Heat Transfer Characteristics of Laminar Nanofluids Flow in Oblique Finned Microchannel Heat Sink: Effects of Different Base Fluids and Volume Fraction of Nanoparticles
}

\author{
Ji Ying Choong ${ }^{1}$, Kok Hwa Yu ${ }^{1,}{ }^{*}$, Mohd Zulkifly Abdullah ${ }^{1}$ \\ School of Mechanical Engineering, Engineering Campus, Universiti Sains Malaysia, 14300 Penang, Malaysia
}

\section{ARTICLE INFO}

\section{Article history:}

Received 26 May 2020

Received in revised form 10 September 2020

Accepted 15 September 2020

Available online 24 October 2020

\section{Keywords:}

Nanofluids; laminar flow; heat transfer enhancement; microchannel

\section{ABSTRACT}

This paper demonstrates a numerical study of heat transfer characteristics of laminar flow in oblique finned microchannel heat sink using nanofluid with $\mathrm{Al}_{2} \mathrm{O}_{3}$ nanoparticles added to various base fluids including water, ethylene glycol and turbine oil as coolant fluid. The width of the primary channel was $0.5 \mathrm{~mm}$ and the secondary channel was less than $0.15 \mathrm{~mm}$ in the oblique finned microchannel heat sink with an aspect ratio of 3 . ANSYS Fluent was employed to model the flow in the geometry of microchannel. Single phase model and constant heat flux boundary condition were used in this numerical study. The modeling was validated by comparing the published data for conventional and enhanced microchannel heat sink. The base fluid acted as a comparison baseline to the nanofluid with volume fraction of $1.0 \%$ and $4.0 \%$. Besides, the study was carried out in laminar flow regime, whereby the Reynold number ranged between 320 to 700 . It was found that turbine oil based nanofluid had the highest Nusselt number among all fluids, followed by ethylene glycol and water to be the least. However, the heat transfer coefficient among all fluids were contrary to the Nusselt number where water achieved the highest heat transfer coefficient. The addition of nanoparticles increased the heat transfer coefficient of all fluids but it did not enhance their Nusselt number except water.

\section{Introduction}

Heat removal is a key factor in nearly all industrial applications. In twenty first century, applications such as nuclear reactors, machinery, automobile, high performance computer chips and etc., generate high heat intensity which require effective and capable heat removal solutions to maintain their daily operations and performance. Due to the high surface to volume ratio, small-scale

\footnotetext{
* Corresponding author.

E-mail address: yukokhwa@usm.my
}

https://doi.org/10.37934/arfmts.76.3.2537 
microchannel heat sinks are thus extensively used in these applications to remove high power densities.

Microchannel heat sink was first introduced by Tuckerman and Pease [1] in 1981. The microchannel heat sink was made using silicon which is capable of removing power density of 790 $W / m^{2}$. There are several recent studies using numerical and experimental works available in the literature that investigate the forced convective heat transfer in different design parameters of microchannel heat sink [2-8]. The effects of using different shapes of cross section of microchannel heat sinks including circular, hexagon, rectangular, straight slot and triangular shapes were examined [6]. Although there are a lot of available studies on microchannel heat sink design, rectangular crosssection shape is more commonly utilized due to the ease of fabrication and its comparable heat transfer capability to other designs. In recent study, there is a breakthrough on heat transfer enhancement using the heat sink design having breakages of continuous fin into oblique shape sections [9].

Apart from having plain working base fluid, adding nanoparticles to the coolant fluid to enhance the properties of the coolant fluid which is known as nanofluid has been extensively studied [10]. There are plenty of experimental and numerical studies performed on heat transfer enhancement of nanofluids compared to its base fluid [11-14]. Single-phase method is a common method used as a prediction of thermal properties of nanofluid in simulation. Higher accuracy results can be obtained by using two-phase method but it is costlier due to the high computing power requirement [15].

In this study, heat transfer study was carried out in oblique finned microchannel heat sink using water, ethylene glycol and turbine oil as well as their respective nanofluid with added aluminium oxide $\left(\mathrm{Al}_{2} \mathrm{O}_{3}\right)$ nanoparticles at $1.0 \%$ and $4.0 \%$ volume fraction concentration. The results were computed using ANSYS Fluent and validated with the existing numerical and experimental works carried out by Lee et al., [8,9].

\section{Mathematical Model}

\subsection{Geometrical Configuration}

Both conventional microchannel heat sink and oblique finned microchannel heat sink with 500 $\mu \mathrm{m}$ were simulated and validated with that of Lee et al., [8,9]. The details of the heat sink geometry are as shown in Table 1. Once the base case simulation was validated, the effects of nanofluid with different base fluids at oblique finned microchannel heat sink were explored.

Table 1

Dimension details for microchannel heat sinks used in simulation

\begin{tabular}{lll}
\hline Characteristic & Conventional microchannel & Oblique finned microchannel \\
\hline Material & Copper & \\
Footprint, width $\times$ length $(\mathrm{mm})$ & $25 \times 25$ & \\
Main channel width $(\boldsymbol{\mu} m)$ & 500 & \\
Fin width $(\boldsymbol{\mu} m)$ & 500 & \\
Channel depth $(\boldsymbol{\mu} m)$ & 1500 & 12 \\
Aspect ratio & 3 & 250 \\
Number of fins per row & - & 2000 \\
Oblique finned channel width $(\boldsymbol{\mu m})$ & - & 1450 \\
Fin pitch $(\boldsymbol{\mu} m)$ & - & 27 \\
Fin length $(\boldsymbol{\mu} m)$ & - & 786 \\
Oblique finned angle $(\mathrm{deg})$ & - & \\
Hydraulic diameter $(\boldsymbol{\mu} \mathrm{m})$ & 750 & \\
\hline
\end{tabular}


A single section of heat sink with periodic boundary condition imposed at the side boundaries is employed to mimic the repetitive pattern of the heat sink problem, as illustrated in Figure 1 . This reduces the size of the computation domain needed for both conventional and oblique finned microchannel. For oblique finned microchannel, the entrance of the inlet was extended to ensure the flow is fully developed before entering the microchannel. An extended length is also applied at the outlet, to prevent reverse flow occurred while fluid exiting the microchannel, as shown in Figure 1.

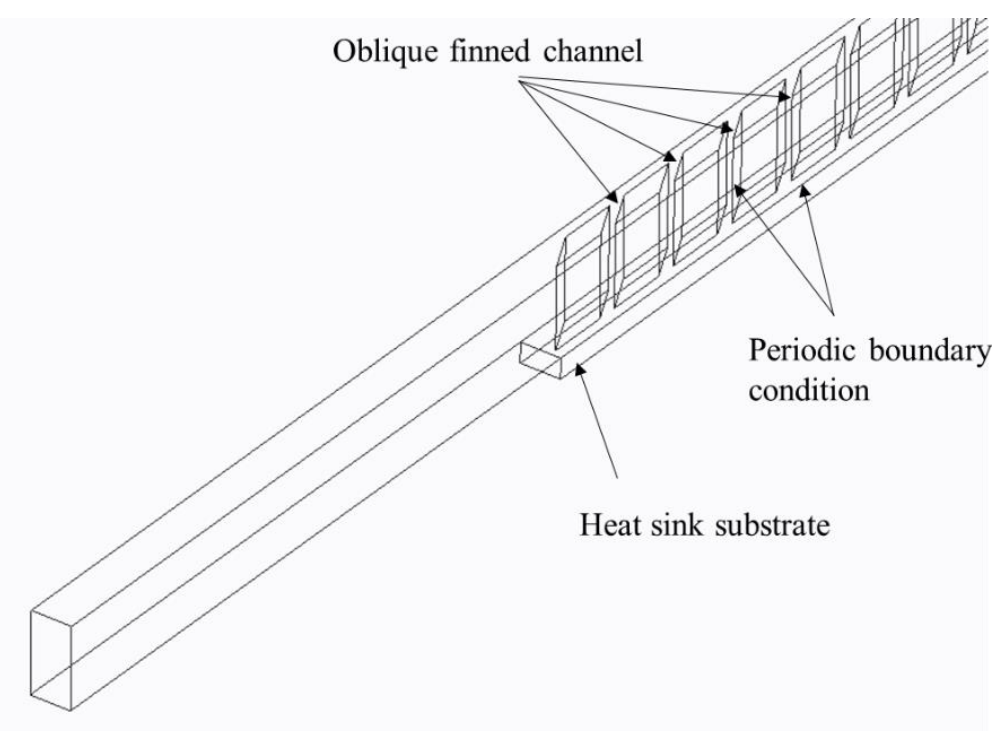

Fig. 1. Computational domain for oblique finned microchannel heat sink

\subsection{Governing Equations and Boundary Condition}

Single-phase method in simulating nanofluids was employed in this study. The following governing equations were used for the single-phase model [16].

Conservation of mass:

$\nabla \cdot(\rho \vec{V})=0$

Conservation of momentum:

$\nabla \cdot(\rho \vec{V} \vec{V})=-\nabla P+\nabla \cdot(\mu \nabla \vec{V})$

Energy equation:

$\nabla \cdot(\rho \vec{V} c T)=\nabla \cdot(k \nabla T)$

The density, pressure and dynamic viscosity are denoted by $\rho, P$ and $\mu$, respectively. The $\vec{V}$ is the velocity field. Meanwhile, the temperature, specific heat capacity and thermal conductivity are represented by $T, c$ and $k$, respectively.

The model was assumed to be incompressible and viscous dissipation was negligible in energy equation. The integrated effects of momentum and energy exchange with base fluid was neglected. 
Constant inlet velocity and pressure outlet boundary condition were applied, constant wall heat flux boundary condition $\left(65 \mathrm{~W} / \mathrm{cm}^{2}\right)$ at base heat sink was considered, except for the top surfaces that employed adiabatic condition.

\subsection{Thermo-Physical Properties of Fluid}

The thermophysical properties of the base fluids and nanoparticles were shown in Table 2 . These properties were adopted from Ramirez-Tijerina et al., [17].

Table 2

Thermophysical properties of base fluid and nanoparticles

\begin{tabular}{lllll}
\hline Material & $\begin{array}{l}\text { Density, } \rho \\
\left(\mathrm{kg} / \mathrm{m}^{3}\right)\end{array}$ & $\begin{array}{l}\text { Specific Heat, } c(\mathrm{~J} / \\
\mathrm{kg} \cdot \mathrm{K})\end{array}$ & $\begin{array}{l}\text { Dynamic } \\
\text { Viscosity, } \mu(\mathrm{kg} / \\
\mathrm{m} \cdot \mathrm{s})\end{array}$ & $\begin{array}{l}\text { Thermal } \\
\text { Conductivity, } k(W / \\
\mathrm{m} \cdot \mathrm{K})\end{array}$ \\
\hline Water & 997 & 4170 & $1.00 \times 10^{-3}$ & 0.606 \\
Ethylene-Glycol & 1111 & 2415 & $1.57 \times 10^{-2}$ & 0.252 \\
Turbine Oil & 868 & 2000 & $2.70 \times 10^{-2}$ & 0.120 \\
$\mathrm{Al}_{2} \mathrm{O}_{3}$ nanoparticles & 3970 & 791 & - & 40.00 \\
\hline
\end{tabular}

(i) Density

The density of nanofluids $\left(\rho_{n f}\right)$ was computed using mixture rule as follows [18].

$\rho_{n f}=\rho_{b f}(1-\phi)+\rho_{p} \phi$

where $\phi$ is the volume fraction of nanoparticles. The subscript $n p, b f$ and $p$ represent the nanofluid, base fluid and nanoparticle.

(ii) Specific Heat

The effective specific heat of the nanofluid $\left(c_{n f}\right)$ was calculated using the following equation, assuming thermal equilibrium between base fluid and nanoparticles [18]

$c_{n f}=\frac{(1-\phi)(\rho c)_{b f}+\phi(\rho c)_{p}}{\rho_{n f}}$

(iii) Thermal conductivity and viscosity

The thermal conductivity of alumina-water nanofluid was calculated using the equation proposed by Heyhat's experimental work where the equation fit the experimental results with a correlation coefficient of 0.95 [19]. At the same time, Heyhat formulated the dynamic viscosity equation of alumina-water nanofluids by converting the measured kinematic viscosities to dynamic viscosity. A study by Maïga et al., [20] justified the use of Eq. (8) and Eq. (9) for calculating the thermal conductivity and viscosity of alumina-ethylene-glycol nanofluid. The thermal conductivity of aluminaturbine oil nanofluid was formulated using Eq. (10) as proposed by $\mathrm{Yu}$ and Choi [21], which the experimental thermal conductivity of the oil-based nanofluid was close to the results obtained from the correlations, whereas the effective viscosity of turbine oil based nanofluid was evaluated using the correlation of Wang et al., [22] as stated in Eq. (11). 
For $\mathrm{Al}_{2} \mathrm{O}_{3}$-water nanofluid,

$k_{n f}=\left(1+8.733 \phi_{p}\right) k_{b f}$

$\mu_{n f}=\mu_{b f} e^{\frac{5.989 \phi}{0.278-\phi}}$

For $\mathrm{Al}_{2} \mathrm{O}_{3}$-ethylene-glycol nanofluid,

$k_{n f}=k_{b f}\left(28.905 \phi^{2}+2.8273 \phi+1\right)$

$\mu_{n f}=\mu_{b f}\left(306 \phi^{2}-0.19 \phi+1\right)$

For $\mathrm{Al}_{2} \mathrm{O}_{3}$-turbine oil nanofluid,

$k_{n f}=\frac{k_{b f}\left\{k_{p}+2 k_{b f}+2\left(k_{p}-k_{b f}\right)(1.1)^{3} \phi\right\}}{k_{p}+2 k_{b f}-\left(k_{p}-k_{b f}\right)(1.1)^{3} \phi}$

$\mu_{n f}=\mu_{b f}\left(1+7.3 \phi+123 \phi^{2}\right)$

The governing equations of mass, momentum and energy were solved using finite volume method via ANSYS Fluent. Second-order upwind scheme was employed for computing the parameters. Thus, the average heat transfer coefficient $\left(h_{\text {avg }}\right)$ was calculated using Eq. (13) as follows.

$h_{x}=\frac{q^{\prime \prime}}{T_{w}(x)-T_{m}(x)}$

$h_{\text {avg }}=\frac{1}{L} \int_{0}^{L} h(x) d x$

The Nusselt number $(\mathrm{Nu})$ was defined as

$N u=\frac{h_{a v g} D_{h}}{k_{n f}}$

where $D_{h}$ is the hydraulic diameter.

\section{Results and Discussion}

The numerical simulations of both conventional microchannel heat sink (MCHS) and oblique finned microchannel heat sink (OFMCHS) were conducted in ANSYS Fluent. The present study focused in laminar flow regime with Reynold number ranging between 320 to 700 . This research emphasized the understanding of the effect of heat transfer enhancement and wall shear stress with nanoparticles addition into the base coolant fluid. Grid independence test was first conducted using five different grid resolutions which were applied on both simulations having MCHS and OFMCHS. As illustrated in Figure 2, the Nusselt number and pressure drop converged when fine mesh is used. To ascertain the accuracy of the simulation results, the second finest mesh sizing $(46,760$ and 99,080 element counts for MCHS and OFMCHS, respectively) were used in this study. 


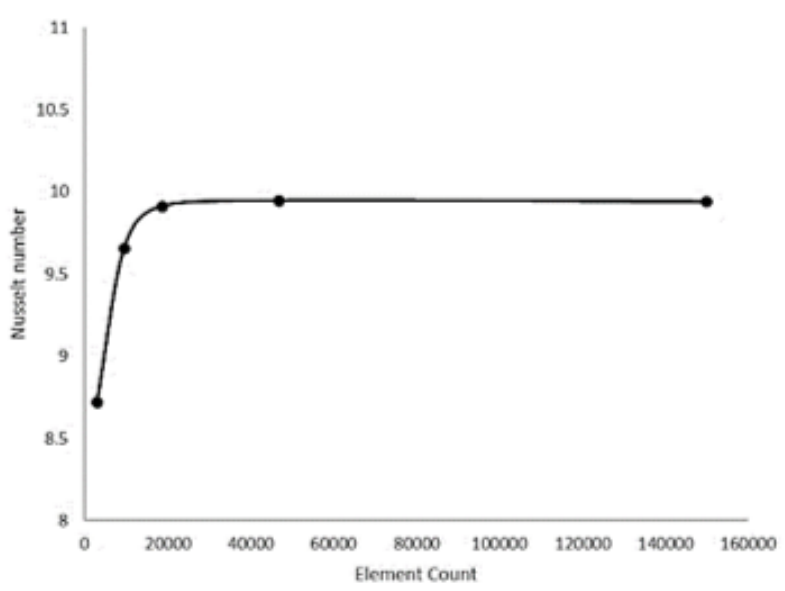

(a)

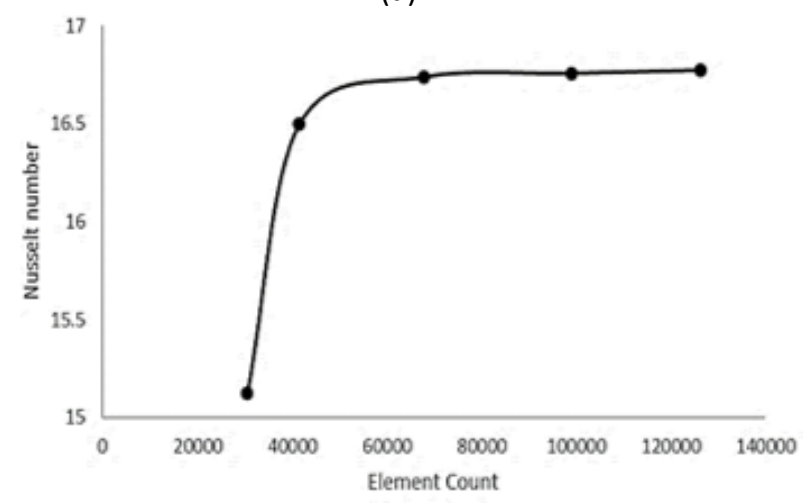

(c)

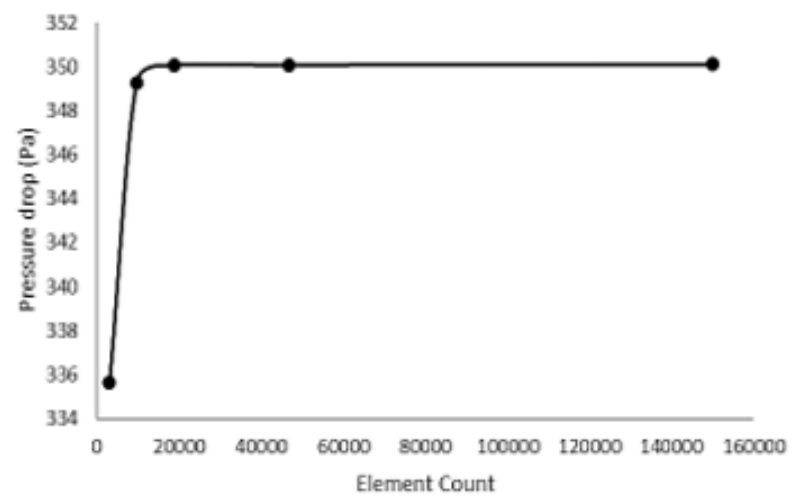

(b)

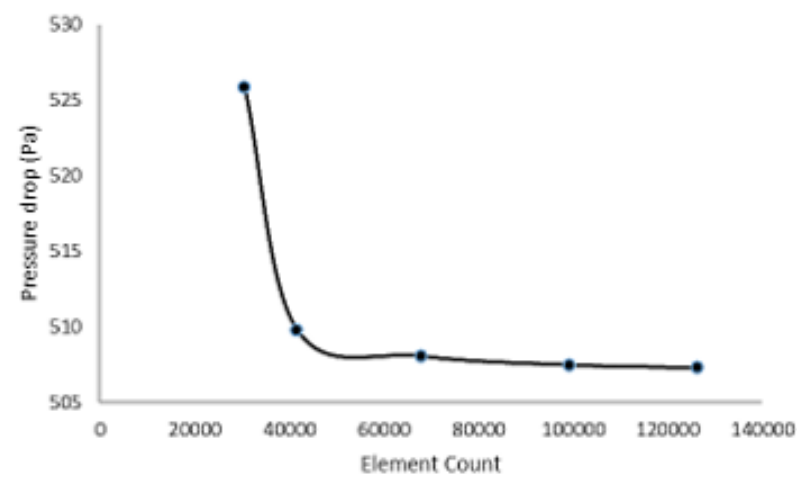

(d)

Fig. 2. Grid independence test conducted on (a) Nusselt number, and (b) pressure drop for $\mathrm{MCHS}$ at $\mathrm{Re}=$ 320 using water. Part (c) and (d) are Nusselt number and pressure drop for OFMCHS, respectively

\subsection{Validation of Numerical Simulation}

Using the recommended grid resolutions, the numerical model was then validated by comparing with the results presented by Lee et al., [8,9] using water as coolant fluid as shown in Figure 3 and Figure 4. In all conditions, relatively small deviation had been noticed for average Nusselt number and pressure drop against Reynold number between both Lee et al., [8,9] and present numerical work. Apparently, Nusselt number of fluid flow in OFMCHS was higher than conventional MCHS at all Reynold number which indicates that heat transfer can be enhanced by introducing the breakage of fin (oblique fins) in the MCHS.

In this study, the simulations showed a vast difference between the temperature contour of MCHS and OFMCHS as shown in Figure 5. The maximum wall temperature of OFMCHS was $45^{\circ} \mathrm{C}$ while conventional $\mathrm{MCHS}$ had maximum wall temperature at $56.2^{\circ} \mathrm{C}$. The temperature contour of conventional MCHS showed relatively high temperature in the vicinity of the channel wall. For OFMCHS, the temperature profile over the fluid domain is more uniform. This can be due to better fluid mixing for the OFMCHS as observed in the velocity streamline plot as shown in Figure 6, thus reducing the temperature gradient between the fluid and the solid wall, which is highly desirable in maintaining low temperature in the cooling system. 
Apart from the temperature and velocity fields, the local pressure drop profile of conventional MCHS and OFMCHS is also illustrated in Figure 7. The periodic dips and spikes of the static pressure was observed in OFMCHS which is in agreement with numerical work of Lee et al., [8]. As can be observed from this figure, the pressure dropped as the fluid left at each secondary channel outlet and the pressure recovered once the secondary flow combined into the adjacent main channel in OFMCHS.

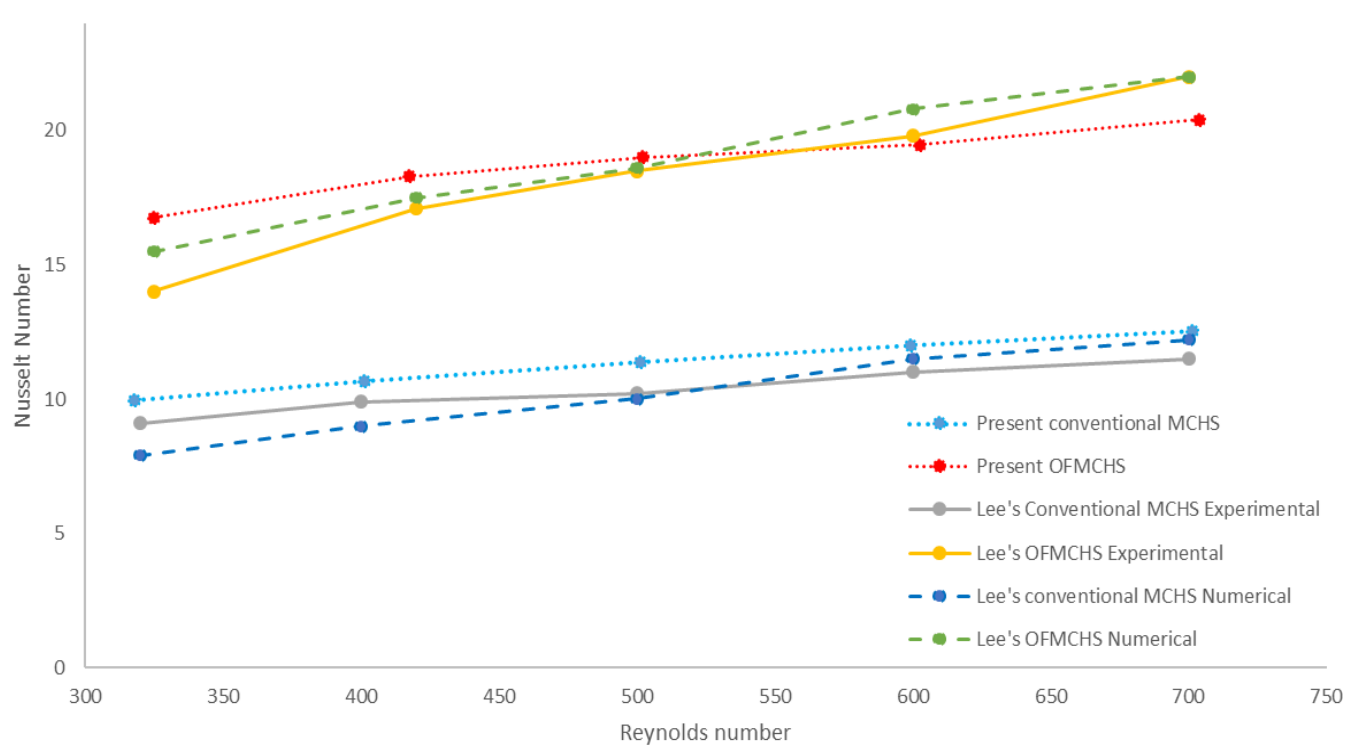

Fig. 3. Average Nusselt number vs Reynold number comparison for model validation

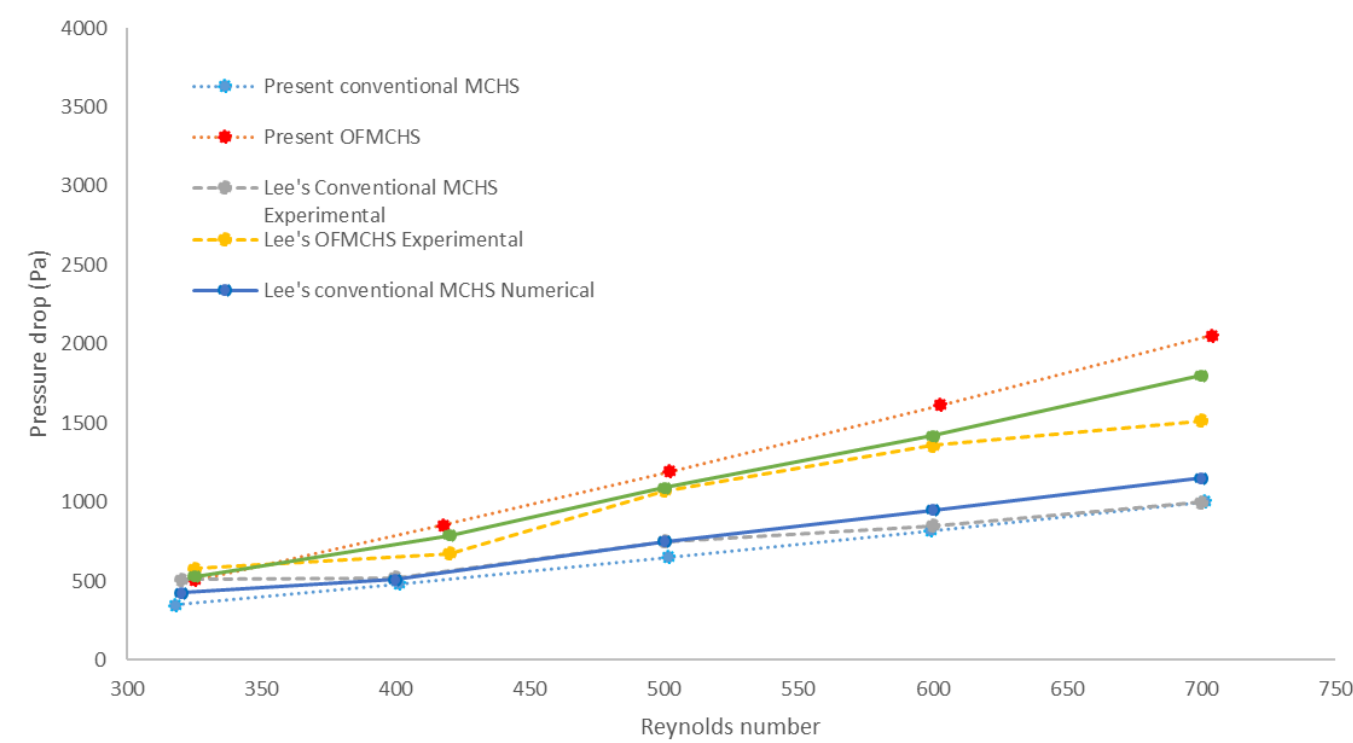

Fig. 4. Pressure drop across the microchannel vs Reynold number comparison for model validation 


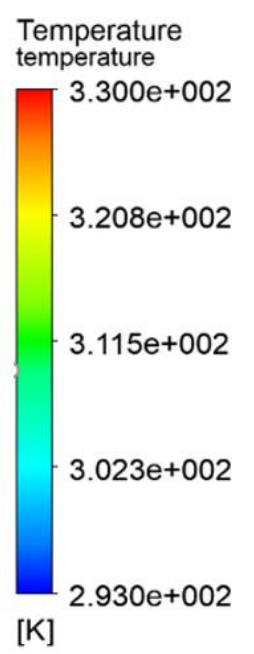

$[\mathrm{K}]$

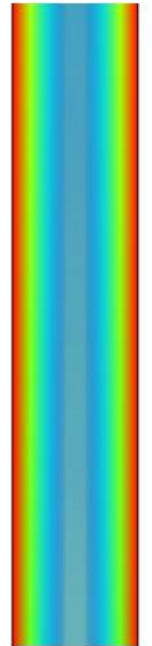

(a)

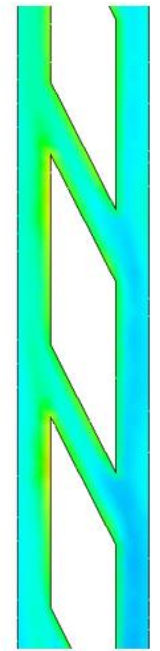

(b)

Fig. 5. Temperature (K) contour of laminar flow of (a) conventional MCHS and (b) OFMCHS at $\mathrm{Re}=320$

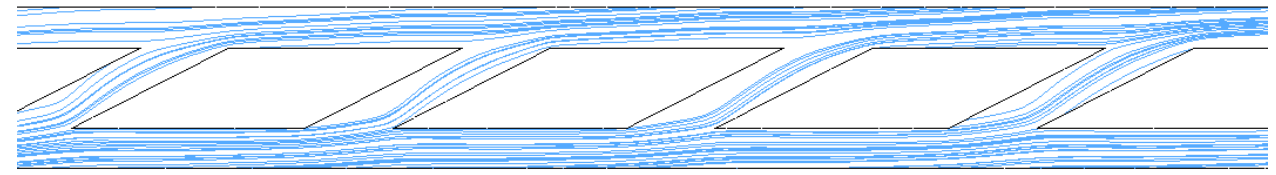

Fig. 6. Velocity streamline of water flow in OFMCHS at $\mathrm{Re}=320$

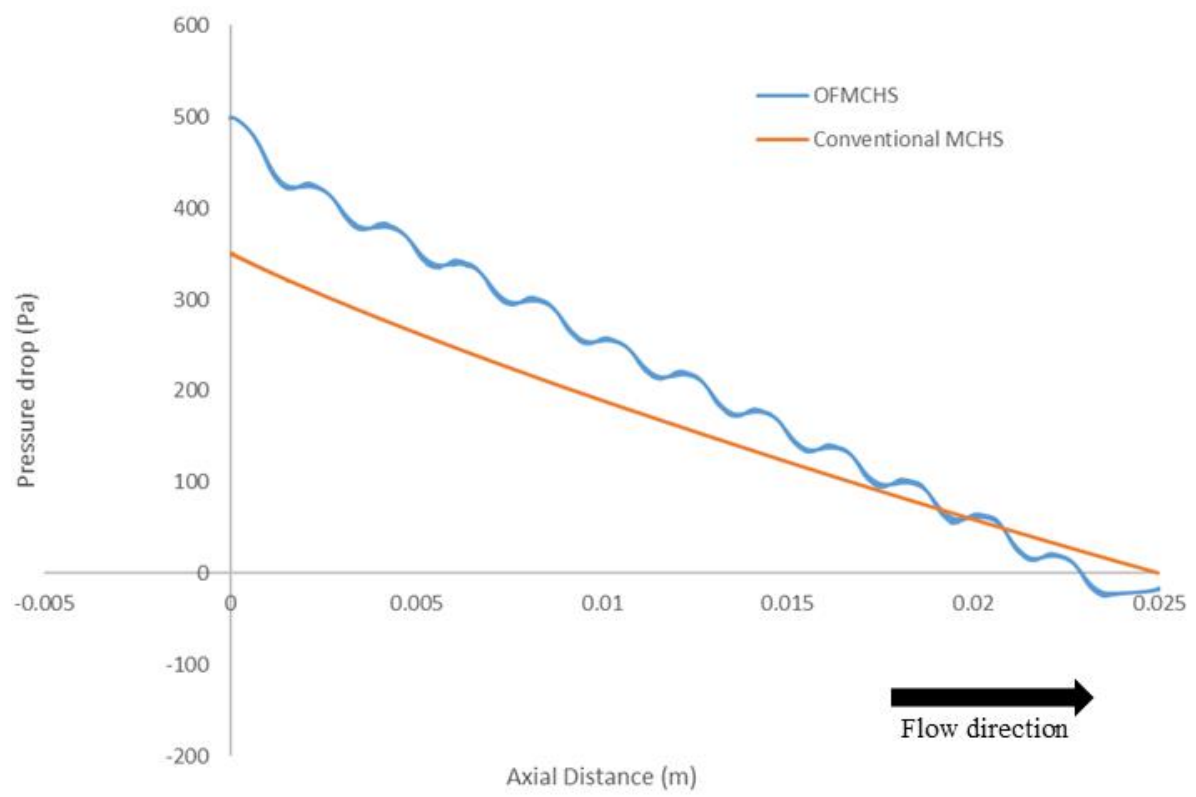

Fig. 7. Pressure drop profile of both MCHS and OFMCHS

\subsection{Fluid Flow and Heat Transfer Characteristics}

As OFMCHS configuration promote better fluid mixing which resulted in a low temperature gradient between wall and core fluid temperature, it is thus insightful to investigate the additional of nanoparticles for heat transfer in OFMCHS. In this study, $\mathrm{Al}_{2} \mathrm{O}_{3}$-nanofluid with three different base fluids with volume concentration of nanoparticles at $0 \%, 1 \%$ and $4 \%$ have been investigated. The average Nusselt numbers against Reynolds numbers for all the nanofluids in OFMCHS were plotted 
in Figure 8. It appeared that average Nusselt number increased with the increase of Reynolds number due to the reduction of thermal boundary layer thickness. Turbine oil based nanofluids recorded the highest average Nusselt number among all the fluids followed by Ethylene glycol and water based nanofluids. This was due to turbine oil and ethylene glycol had lower thermal boundary layer thickness than water, owing to the high Prandtl number of turbine oil and ethylene glycol, which is 450 and 72.22, respectively. Water only has Prandtl number of 6.88. In contrast, water based nanofluids had the highest convective heat transfer coefficient as plotted in Figure 9 although they had the lowest average Nusselt numbers compared to all fluids due to higher value of thermal conductivity. Nevertheless, it is essential to take into consideration for the higher wall shear stress values, in spite of the better Nusselt number observed in both turbine oil and ethylene glycol based nanofluid.

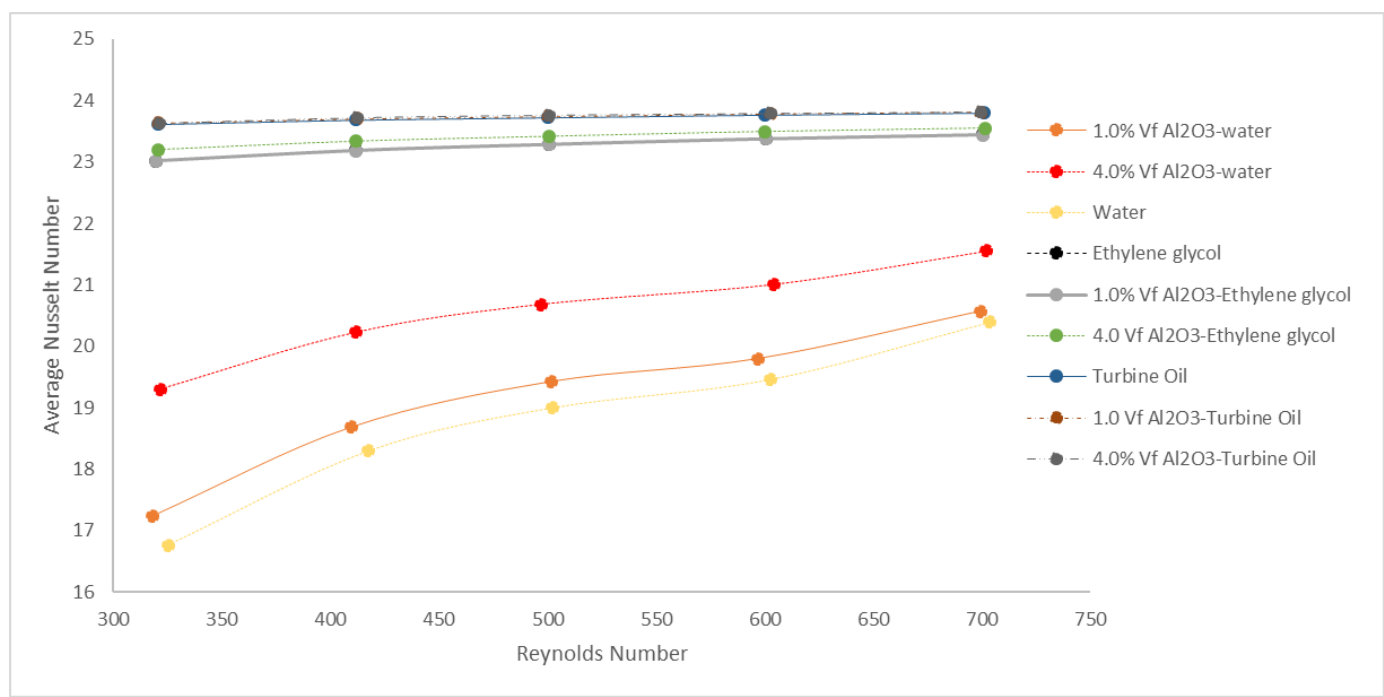

(a)

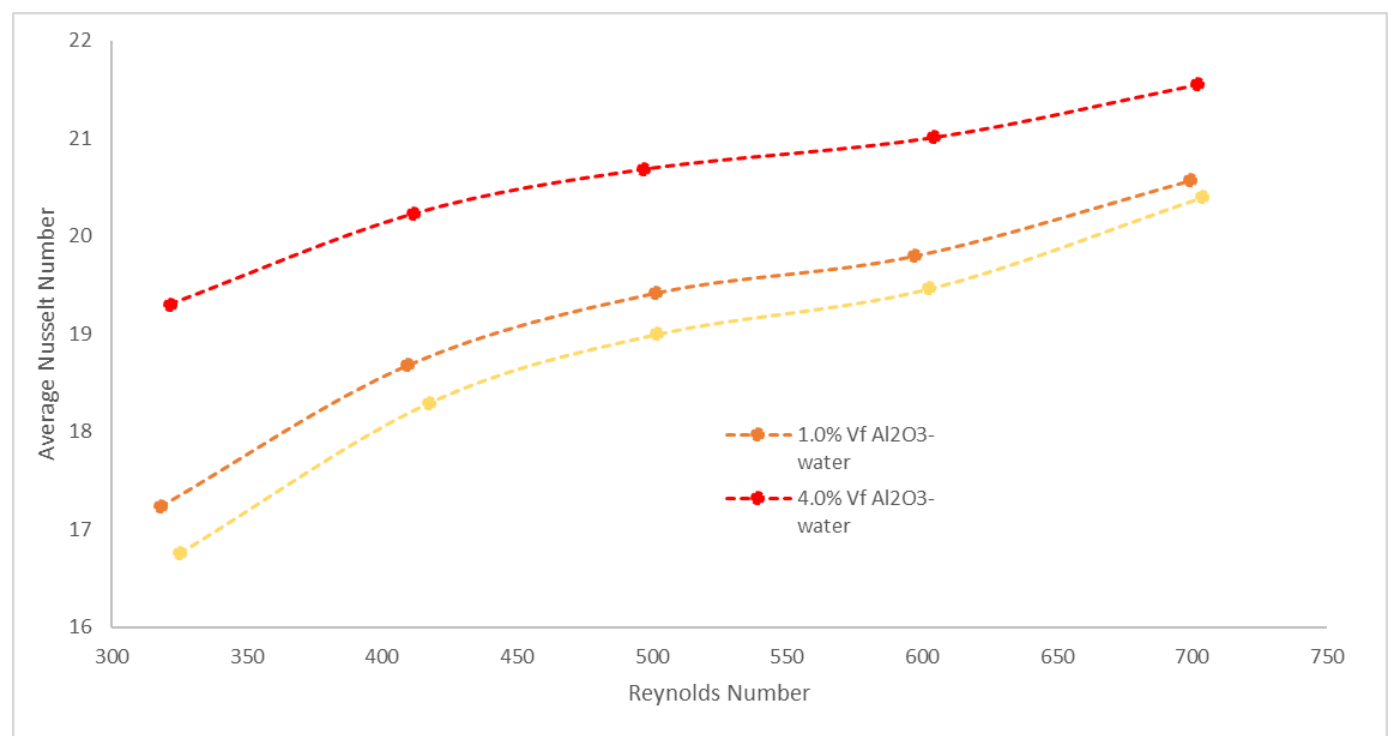

(b) 


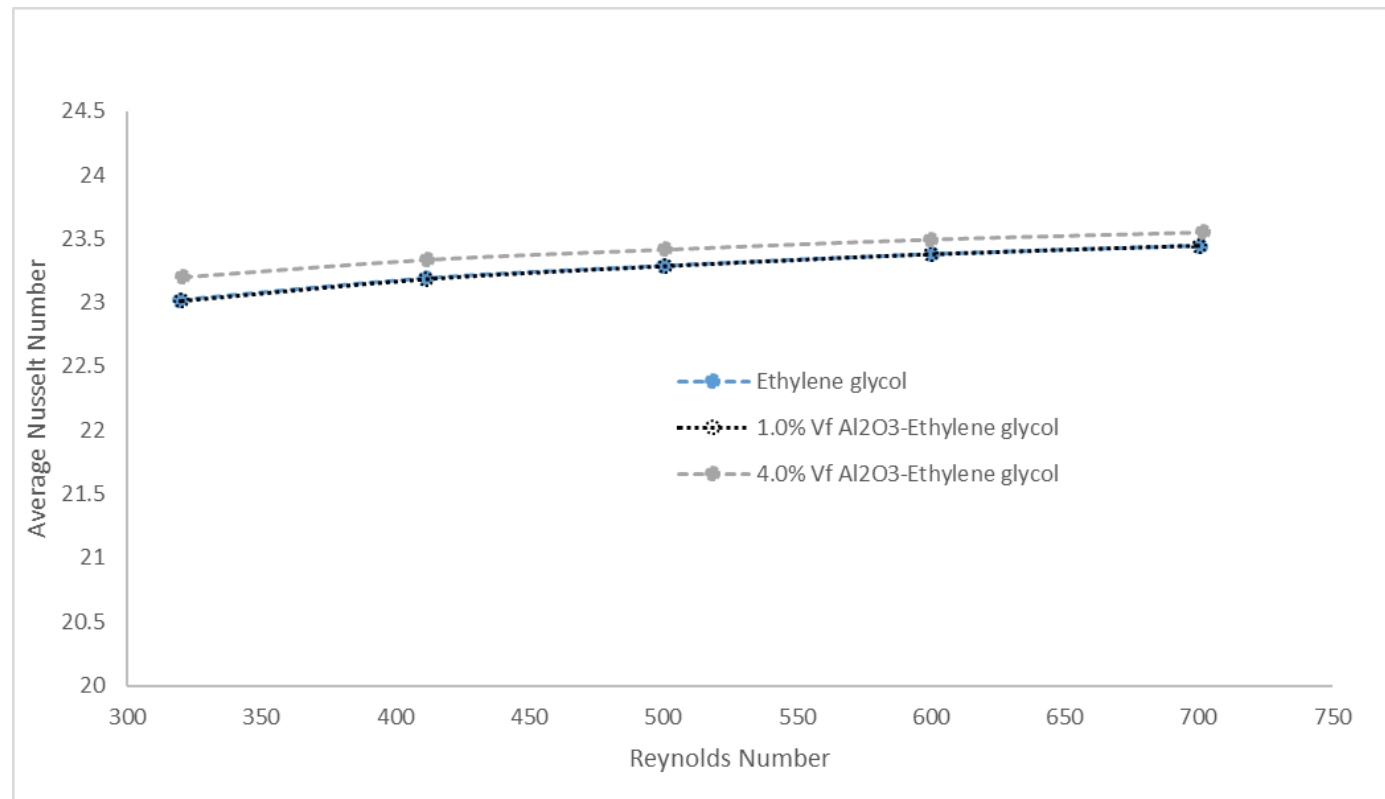

(c)

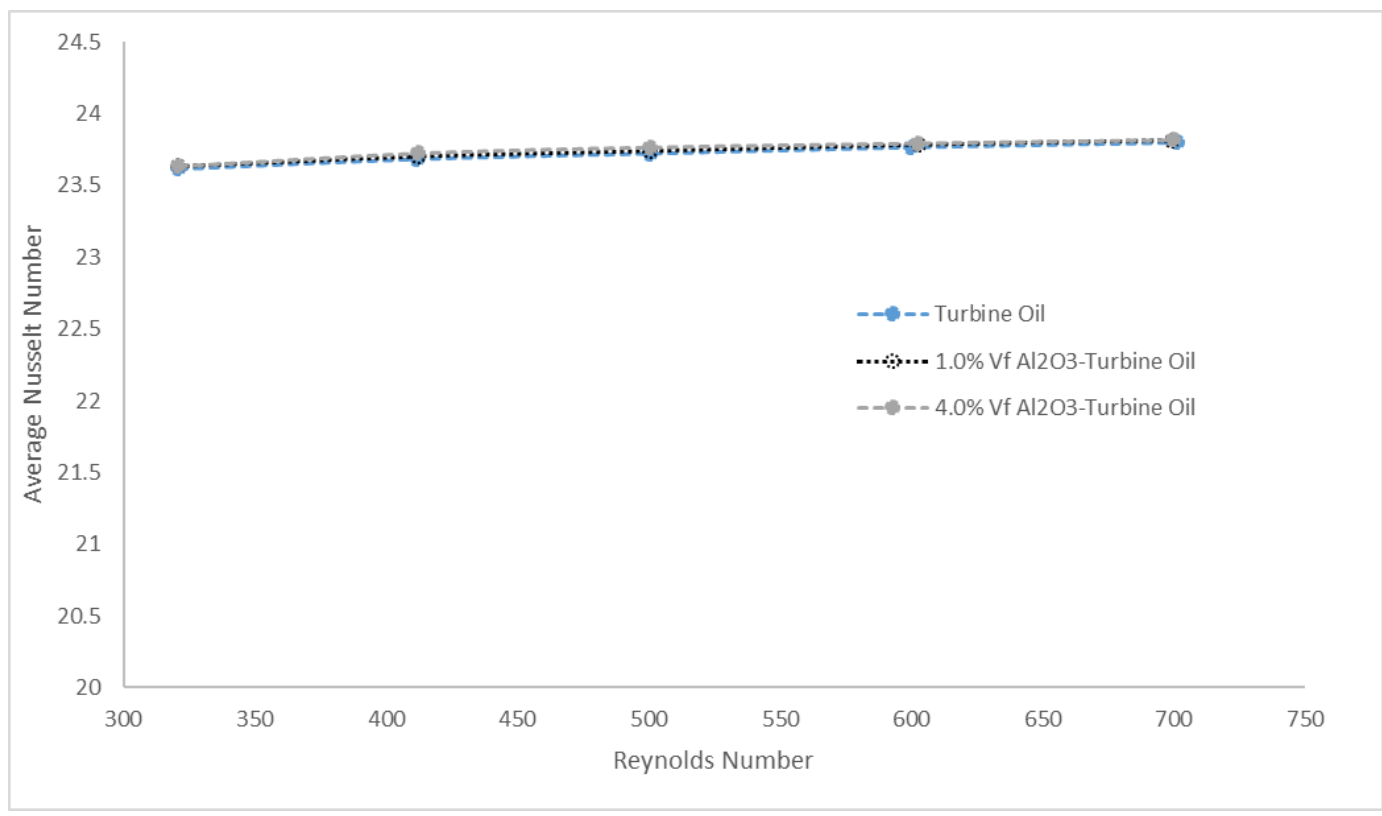

(d)

Fig. 8. Average Nusselt number for (a) all nanofluids, (b) $\mathrm{Al}_{2} \mathrm{O}_{3}$-water nanofluid, (c) $\mathrm{Al}_{2} \mathrm{O}_{3}$ ethylene glycol nanofluid, (d) $\mathrm{Al}_{2} \mathrm{O}_{3}$-turbine oil nanofluid, in OFMCHS

Based on the simulation results, the addition of $\mathrm{Al}_{2} \mathrm{O}_{3}$ nanoparticles to turbine oil did not significantly increase its Nusselt number and there is only marginal increase in Nusselt number observed for ethylene glycol as shown in Figure 8(c) and Figure 8(d). Although the addition of nanoparticles enhanced the average heat transfer coefficient in turbine oil and ethylene glycol, it did not affect the average Nusselt number of the fluid flow. The percentage increase in heat transfer coefficient for both nanofluids at $4 \%$ volume fraction was remarkably similar, i.e. $16.81 \%$ and $16.63 \%$ for turbine oil and ethylene glycol, respectively. On the other hand, Figure 8(b) showed the Nusselt number of water improved by $9.43 \%$ after adding $\mathrm{Al}_{2} \mathrm{O}_{3}$ nanoparticles to the base fluid; the average heat transfer coefficient increased by $10.43 \%$ and $46.17 \%$ in $1 \%$ and $4 \%$ volume fraction $\mathrm{Al}_{2} \mathrm{O}_{3}$-water respectively, as plotted in Figure 9. 
The present results, as illustrated in Figure 10, clearly demonstrate the effect of $\mathrm{Al}_{2} \mathrm{O}_{3}$ nanoparticles inclusion to the wall shear stress of the fluid flow. The wall shear stress of ethylene glycol and turbine oil based nanofluid became 1.5 folded at high volume fraction of $\mathrm{Al}_{2} \mathrm{O}_{3}$ nanoparticles $(\phi=4 \%)$. The viscosity of ethylene glycol and turbine oil rise with the increasing of nanoparticles volume fraction, hence high-volume fraction of ethylene glycol and turbine oil based nanofluid were not suitable for improving heat removal system, in correspondence with RamirezTijerina et al., numerical work [17]. The wall shear stress penalty found in high volume fraction $\mathrm{Al}_{2} \mathrm{O}_{3}$ water was insignificant compared to its base fluid.

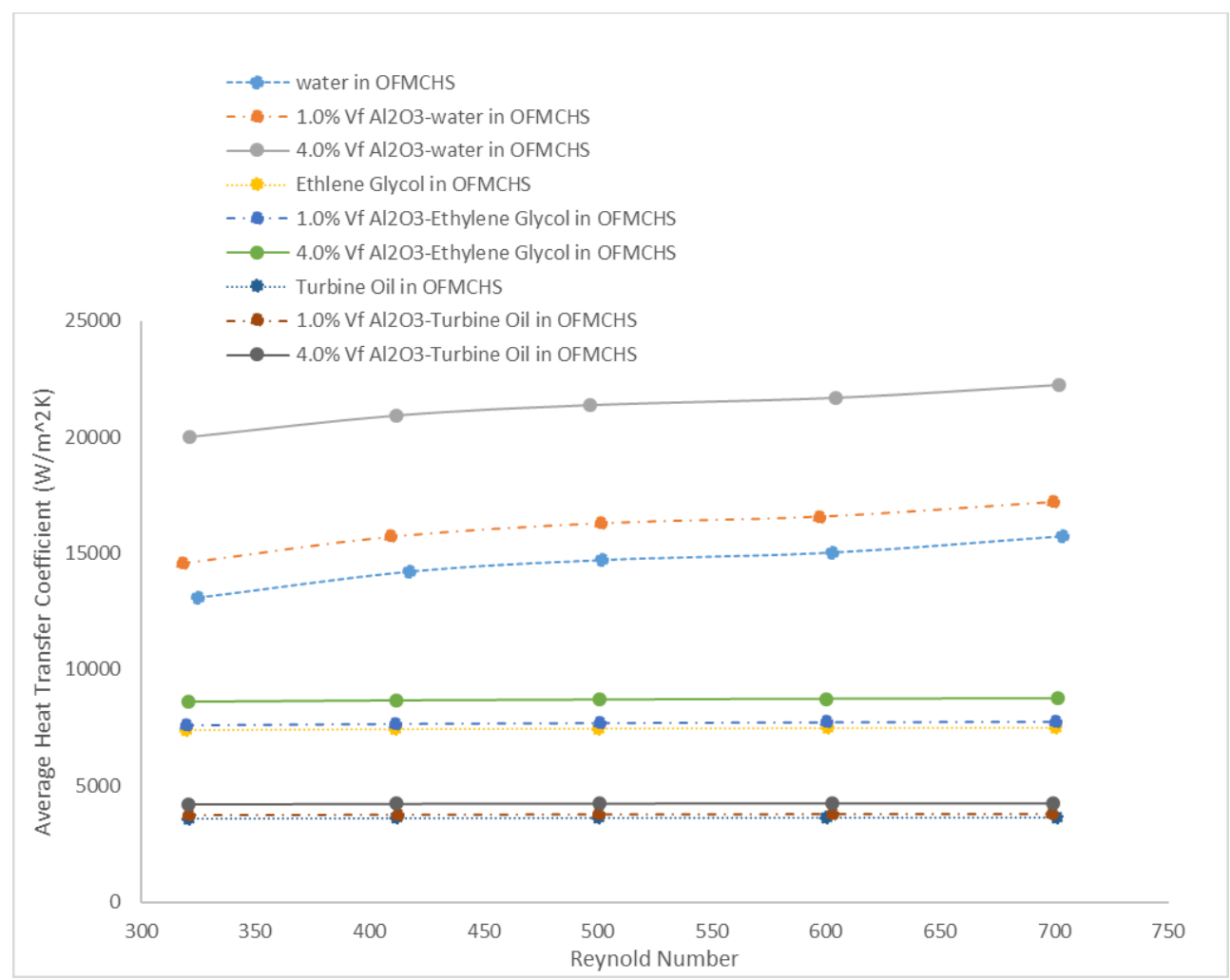

Fig. 9. Average heat transfer coefficient vs Reynolds number among all nanofluids in OFMCHS

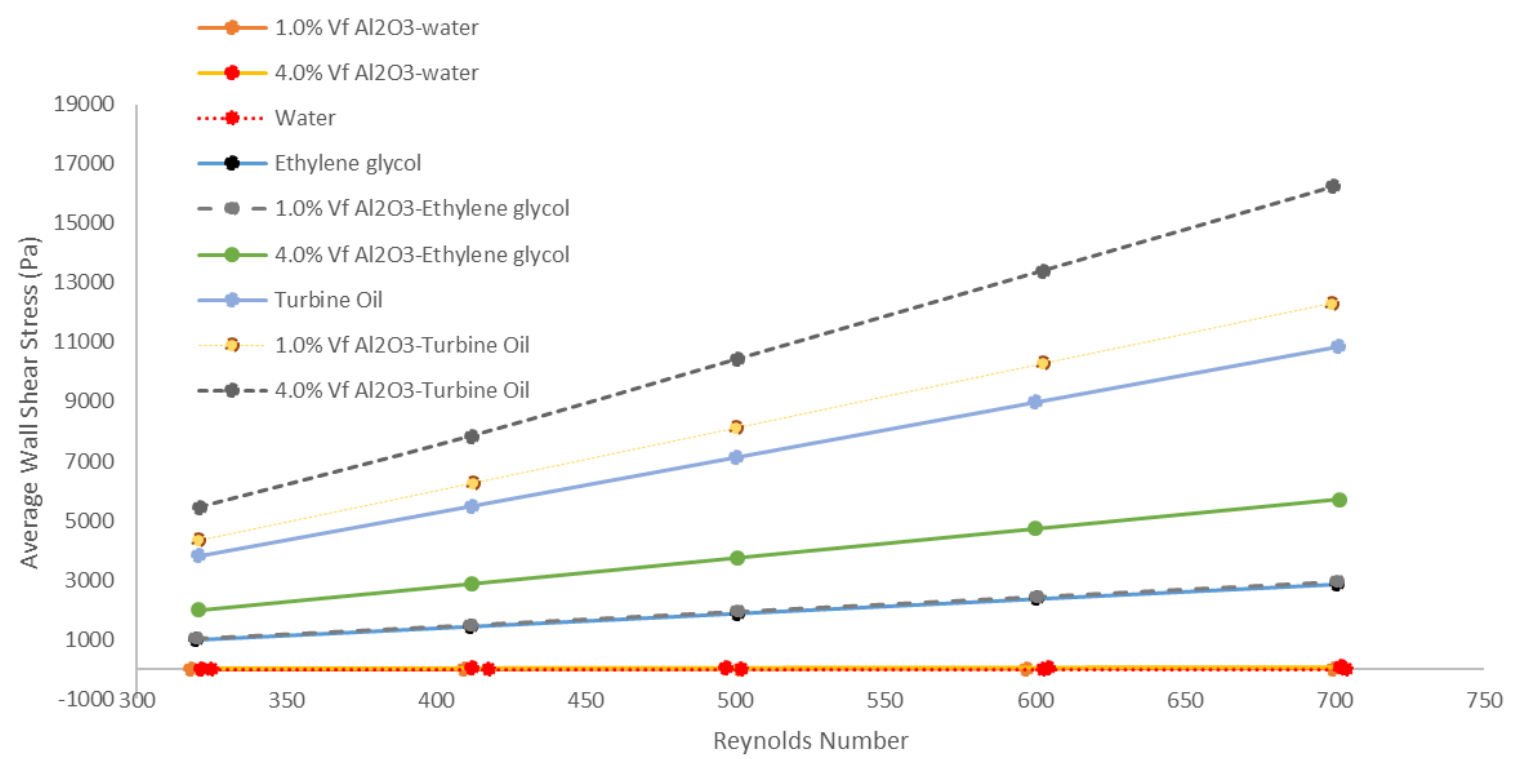

Fig. 10. Wall shear stress vs Reynolds number among all nanofluids in OFMCHS 


\section{Conclusion}

In the present study, heat transfer of nanofluid in laminar flow regime $(320<R e<700)$ with different base fluids was investigated at $0 \%, 1 \%$ and $4 \%$ volume fraction of $\mathrm{Al}_{2} \mathrm{O}_{3}$ nanoparticles in OFMCHS geometry. The study matched with Lee's research by using water as the coolant fluid in conventional MCHS and OFMCHS [8,9]. Turbine oil based nanofluid gave the highest average Nusselt number, followed by ethylene glycol and water, though the latter recorded highest average heat transfer coefficient, subsequently ethylene glycol and turbine oil. The incorporation of nanoparticles led to an increase of $9.43 \%$ in $\mathrm{Al}_{2} \mathrm{O}_{3}$-water average Nusselt number and $46.17 \%$ in average heat transfer coefficient with $\phi=4 \%$. Although increasing the volume fraction of nanoparticles enhanced the average heat transfer coefficient of turbine oil and ethylene glycol based nanofluid, it did not reveal notable effect on their average Nusselt number in view of the thickening of thermal boundary layer.

Despite the higher Nusselt numbers found in $\mathrm{Al}_{2} \mathrm{O}_{3}$-ethylene glycol and $\mathrm{Al}_{2} \mathrm{O}_{3}$-turbine oil, the impact of addition of the nanoparticles to the wall shear stress ( 1.5 times of the corresponding based fluid for both nanofluid at $\phi=4 \%$ ) shall be reckoned as well since the nanoparticles would govern the fluid viscosity. Hence, it is not recommended to improve the heat transfer by mixing nanoparticles to ethylene glycol and turbine oil. On the other hand, nanoparticles loadings in water represented significant effect in enhancing the average Nusselt number and heat transfer coefficient with negligible wall shear stress penalty.

\section{Acknowledgement}

The authors acknowledge the Ministry of Education (MOE) of Malaysia under Fundamental Research Grant Scheme (FRGS Grant: FRGS/1/2019/TK03/USM/03/3) and School of Mechanical Engineering for the financial support.

\section{References}

[1] Tuckerman, David B., and Roger Fabian W. Pease. "High-performance heat sinking for VLSI." IEEE Electron Device Letters 2, no. 5 (1981): 126-129.

https://doi.org/10.1109/EDL.1981.25367

[2] Adewumi, O. O., T. Bello-Ochede, and Josua P. Meyer. "Constructal design of single microchannel heat sink with varying axial length and temperature-dependent fluid properties." International Journal Of Heat And Technology 34, no. 1 (2016): 167-172.

https://doi.org/10.18280/ijht.34Sp0122

[3] Liu, Dong, and Suresh V. Garimella. "Analysis and optimization of the thermal performance of microchannel heat sinks." International Journal of Numerical Methods for Heat \& Fluid Flow 15, no. 1 (2005): 7. https://doi.org/10.1108/09615530510571921

[4] Emran, Md, and Mohammad Ariful Islam. "Numerical investigation of flow dynamics and heat transfer characteristics in a microchannel heat sink." Procedia Engineering 90 (2014): 563-568.

https://doi.org/10.1016/i.proeng.2014.11.773

[5] Gawali, B. S., V. B. Swami, and S. D. Thakre. "Theoretical and Experimental Investigation of Heat Transfer Characteristics through a Rectangular Microchannel Heat Sink." International Journal of Innovative Research in Science, Engineering and Technology 3, no. 8 (2014).

[6] Moradikazerouni, Alireza, Masoud Afrand, Jalal Alsarraf, Omid Mahian, Somchai Wongwises, and Minh-Duc Tran. "Comparison of the effect of five different entrance channel shapes of a micro-channel heat sink in forced convection with application to cooling a supercomputer circuit board." Applied Thermal Engineering 150 (2019): 1078-1089.

https://doi.org/10.1016/i.applthermaleng.2019.01.051

[7] Vinoth, R., and D. Senthil Kumar. "Channel cross section effect on heat transfer performance of oblique finned microchannel heat sink." International Communications in Heat and Mass Transfer 87 (2017): 270-276.

https://doi.org/10.1016/j.icheatmasstransfer.2017.03.016 
[8] Lee, Y. J., P. S. Lee, and S. K. Chou. "Numerical study of fluid flow and heat transfer in the enhanced microchannel with oblique fins." Journal of Heat Transfer 135, no. 4 (2013).

https://doi.org/10.1115/1.4023029

[9] Lee, Y. J., P. S. Lee, and S. K. Chou. "Enhanced thermal transport in microchannel using oblique fins." Journal of Heat Transfer 134, no. 10 (2012).

https://doi.org/10.1115/1.4006843

[10] Abubakar, S. B., N. A. Che Sidik, and A. S. Ahmad. "The use of Fe304-H2O4 nanofluid for heat transfer enhancement in rectangular microchannel heatsink." Journal of Advanced Research in Materials Science 23, no. 1 (2016): 15-24.

[11] Purohit, Nilesh, Varun Anand Purohit, and Kamlesh Purohit. "Assessment of nanofluids for laminar convective heat transfer: A numerical study." Engineering Science and Technology, an International Journal 19, no. 1 (2016): $574-$ 586.

https://doi.org/10.1016/i.jestch.2015.08.010

[12] Arjun, K. S., and K. Rakesh. "Heat transfer enhancement using alumina nanofluid in circular micro channel." Journal of Engineering Science and Technology 12, no. 1 (2017): 265-279.

[13] Ting, Hsien-Hung, and Shuhn-Shyurng Hou. "Numerical study of laminar flow and convective heat transfer utilizing nanofluids in equilateral triangular ducts with constant heat flux." Materials 9, no. 7 (2016): 576.

https://doi.org/10.3390/ma9070576

[14] Mondragón, R., C. Segarra, J. C. Jarque, J. E. Julia, L. Hernández, and R. Martínez-Cuenca. "Characterization of physical properties of nanofluids for heat transfer application." In Journal of Physics: Conference Series, vol. 395, no. 1, p. 012017. IOP Publishing, 2012.

https://doi.org/10.1088/1742-6596/395/1/012017

[15] Loya, Adil. "Problems Faced While Simulating Nanofluids." Nanofluid Heat and Mass Transfer in Engineering Problems (2017): 97.

https://doi.org/10.5772/66495

[16] Bianco, Vincenzo, F. Chiacchio, Oronzio Manca, and Sergio Nardini. "Numerical investigation of nanofluids forced convection in circular tubes." Applied Thermal Engineering 29, no. 17-18 (2009): 3632-3642. https://doi.org/10.1016/i.applthermaleng.2009.06.019

[17] Ramirez-Tijerina, Ramon, Carlos I. Rivera-Solorio, Jogender Singh, and K. D. P. Nigam. "Numerical study of heat transfer enhancement for laminar nanofluids flow." Applied Sciences 8, no. 12 (2018): 2661.

https://doi.org/10.3390/app8122661

[18] Khanafer, Khalil, and Kambiz Vafai. "A critical synthesis of thermophysical characteristics of nanofluids." International Journal of Heat and Mass Transfer 54, no. 19-20 (2011): 4410-4428. https://doi.org/10.1016/j.ijheatmasstransfer.2011.04.048

[19] Heyhat, M. M., F. Kowsary, A. M. Rashidi, M. H. Momenpour, and A. Amrollahi. "Experimental investigation of laminar convective heat transfer and pressure drop of water-based Al2O3 nanofluids in fully developed flow regime." Experimental Thermal and Fluid Science 44 (2013): 483-489.

https://doi.org/10.1016/i.expthermflusci.2012.08.009

[20] Maiga, Sidi El Becaye, Samy Joseph Palm, Cong Tam Nguyen, Gilles Roy, and Nicolas Galanis. "Heat transfer enhancement by using nanofluids in forced convection flows." International Journal of Heat and Fluid Flow 26 , no. 4 (2005): 530-546. https://doi.org/10.1016/i.ijheatfluidflow.2005.02.004

[21] Yu, W., and S. U. S. Choi. "The role of interfacial layers in the enhanced thermal conductivity of nanofluids: a renovated Maxwell model." Journal of Nanoparticle Research 5, no. 1-2 (2003): 167-171. https://doi.org/10.1023/A:1024438603801

[22] Wang, Xiang-Qi, and Arun S. Mujumdar. "A review on nanofluids-part I: theoretical and numerical investigations." Brazilian Journal of Chemical Engineering 25, no. 4 (2008): 613-630.

https://doi.org/10.1590/S0104-66322008000400001 